\title{
TESTING OF GLUED JOINTS ON PLASTIC PARTS MANUFACTURED USING FFF TECHNOLOGY
}

\author{
JiŘí Suder ${ }^{a, *}$, Michal VocetKa $^{a}$, Tomáš Kot $^{a}$, FrantiŠek Fojtík $^{b}$, \\ MARTIN FUSEK ${ }^{a, b}$ \\ a VSB - Technical University of Ostrava, Faculty of Mechanical Engineering, Department of Robotics, 17. \\ Listopadu 2172/15, Ostrava, Czech Republic \\ ${ }^{b}$ VSB - Technical University of Ostrava, Faculty of Mechanical Engineering, Department of Applied Mechanics, \\ 17. Listopadu 2172/15, Ostrava, Czech Republic \\ * corresponding author: jiri.suder@vsb.cz
}

\begin{abstract}
The article focuses on the testing of glued joints of plastic parts manufactured by 3D rapid prototyping, using the Fused Filament Fabrication technology. The first part of the article describes the suitability of using a glued joint. Then follows a brief description of the plastic materials used for the manufacturing of the testing samples. The materials include not only the common types, such as Polylactide, Polyethylene Terephthalate, Acrylonitrile Butadiene Styrene, but also Thermoplastic Polyurethane, which has a high elasticity and is usually described as a flexible material. The main section of the article deals with the testing of glued joints on a tensometric machine, which produces stress-strain curves. The shear strength of the joints is evaluated. For each material, multiple samples are prepared with different orientation of individual layers created by the $3 \mathrm{D}$ printing process. The impact of the orientation of the layers on the resulting strength of the glued joint is also evaluated. The final section of the article presents comparison and evaluation of the results -analyses of cracks, the impact of the orientation of the layers and the impact of individual materials. The experiment proved the independence of the orientation of the layers on the strength of the glued joint. It was also found out during the experiment that the use of a common adhesive on a flexible material was unsuitable.
\end{abstract}

KEYWORDS: Glued joints, FFF technology, tensile test, flexible plastics, strength test.

\section{INTRODUCTION}

$3 \mathrm{D}$ printing is a well-known and widespread technology of manufacturing [1. Because of the short time it takes to get a functional prototype, this technology is getting more popular not only in industry but also in households due to the availability of cheaper hobby printers. The quality of some of today's hobby $3 \mathrm{D}$ printers is at a very good level, and many prototypes are created on them [2, 3]. One of the disadvantages of $3 \mathrm{D}$ printing nowadays is the limited working area [4, 5]. Big printers are very expensive and the working volume of hobby printers is typically around $25 \times 21 \times$ $21 \mathrm{~cm}$ (Prusa I3 MK3S - the most recent version of one of the best hobby printers on the market [6]). To be able to print bigger parts, it is either necessary to purchase a larger printer or to separate the model into several pieces and then connect them together 4. The latter option is usually the preferred one, for economic reasons. Another reason for splitting one model into several sections that are printed separately can be the complexity of the model - the whole model can be impossible to print altogether, or it would require the usage of a lot of support material. There can also be an aesthetical reason related to how the layers are created.

The separate pieces can be connected by using various methods. The most common method is adhesive bonding, which is a permanent connection. The basic parameter of a glued joint is its strength. One of the possibilities of experimental determination of the strength of plastic samples produced on a $3 \mathrm{D}$ printer is through a tensile test. Due to the anisotropic properties of parts printed by the Fused Filament Fabrication (FFF) method, the strength and at the same time the elongation of the samples depends on the angle (orientation) by which the layers are laid [7, 8]. Thus, it can be assumed that the orientation of the parts can also affect the strength of the glued joints, due to different extensions at the same load. Different elongations at the same load can affect the adhesion of the adhesive to the bonded sample and thus the resulting strength of the bonded joint. A research has already been done on the strength of glued joints [4], which tested the most suitable adhesive for joining two polycarbonate parts made by Fused Deposition Modelling (FDM).

This work expands the knowledge about determining the strength of glued joints of the following materials: Acrylonitrile Butadiene Styrene (ABS), Polylactide Acid (PLA), Polyethylene Terephthalate (PETG) and Thermoplastic Polyurethane (TPU) made by the FFF method. The results of the research are focused on the influence of the orientation of the layers on the strength of the glued joint and the influence of the sample material used on the strength of the glued joint. 


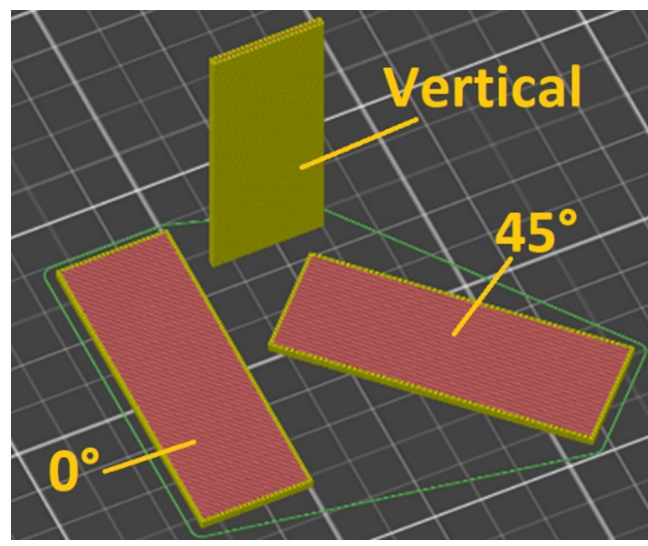

Figure 1. The orientation of samples on the printer base plate.

\section{SAMPLE PREPARATION}

Adhesive bonding is a relatively complex process, which requires strictly following the technological rules to achieve the best properties. The process consists of several technological steps: surface preparation, adhesive preparation, adhesive application, the connection of surfaces, fixation, and curing. Only after all these steps, the model can be used [9, 10].

\subsection{Description OF SAMPLES}

For tensile tests of plastic samples, it is common to follow the ASTM D638 standard [11. This standard assumes the shape of standard dumbbell-shaped test specimens. Since the aim of this work is not to test the material itself, but the glued joint, the shape of the test specimen is adjusted based on the standard ČSN EN 1465 [12. The samples were designed with dimensions $100 \times 25 \times 1 \mathrm{~mm}$ (length $\times$ width $\times$ thickness) and made on a $3 \mathrm{D}$ printer using the FFF method from materials ABS, PLA, PETG and TPU (98A quality). The TPU material is also called flexible, and it is supposed to have considerably different properties when compared with the other materials [13. Samples made from all materials were printed in three different orientations relative to the printing surface to be able to verify the impact of layers on the adhesion and thus the strength of the connection. 20 samples were printed for each material and orientation. Two samples are required for one glued joint. Thus, a total of 240 samples were printed to create 120 glued joints. The different orientations are shown in Fig. 1 .

The orientation marked as $0^{\circ}$ represents a location parallel to the border of the printer mat, the filling is square with a $20 \%$ density (this is the standard setting (14). The orientation $45^{\circ}$ represents a rotation by this angle relative to the mat border, and the filling is the same as in the previous case. The third, vertical, orientation uses filling with a $100 \%$ density, which is more appropriate in this case.

Overlapping of two glued samples is shown in Fig. 2 where the blue colour represents the adhesive. The length of the overlapping area is $12.5 \mathrm{~mm}$ according to

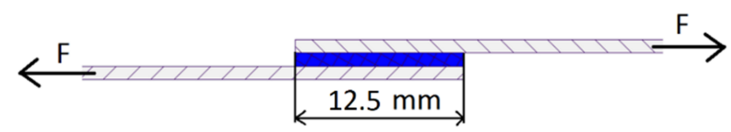

Figure 2. Overlapping of the glued samples.

the ČSN EN 1465 [12] norm for the testing of glued samples by a tensile test. The main type of stress of the adhesive is shear, but there is also a small amount of bending because of the misalignment of the samples - this causes the adhesive to peel off. In this case, this effect is not very significant and can be neglected.

\subsection{TYPE OF ADHESIVE}

There are many types of adhesives on the market that can be used for plastic materials. According to a research, a suitable adhesive for bonding of polycarbonate samples printed by the FDM method [4] is Loctite 401. In this research, a similar adhesive Loctite 406 was used, because it is more suitable for the bonding of samples made from selected materials according to the manufacturer's recommendations [15]. All the tested samples were first tested for wettability, which proved to be perfect - the adhesive spreads on the surface and does not create drops.

\subsection{Surface Preparation AND GLUeing}

Surfaces of the samples were prepared by mechanical grinding using a medium-grained sandpaper. The contact areas were then cleaned and degreased by acetone and a degreaser. Manipulation with the samples was then done by using gloves to prevent further contamination of the surfaces.

Then, a thin layer of the adhesive was applied on the contact surfaces, and the samples were immediately pressed together and fixed for 24 hours, which is the time recommended by the adhesive manufacturer 16 .

\section{Methodology}

All samples were subjected to a tensile test on the Testometric machine M500/50CT (Fig. 3 ) in the laboratory of the Department of Applied Mechanics, Faculty of Mechanical Engineering, VSB - Technical University of Ostrava. The load force $F$ was increased until the material broke, or the adhesive bond failed and the samples separated. The load force $F(\mathrm{~N})$ and elongation $\Delta_{L}(\mathrm{~mm})$ were recorded. The longitudinal strain $\varepsilon(-)$ is calculated as:

$$
\varepsilon=\frac{\Delta_{L}}{L_{O}}=\frac{L-L_{O}}{L_{O}}(-)
$$

where $\Delta_{L}$ is the elongation of samples, $L$ is the length of samples after the test and $L_{O}$ is the initial length of samples.

\section{Results}

In Fig. 4 the graph showing the relation between the load force and the linear strain for the ABS material 


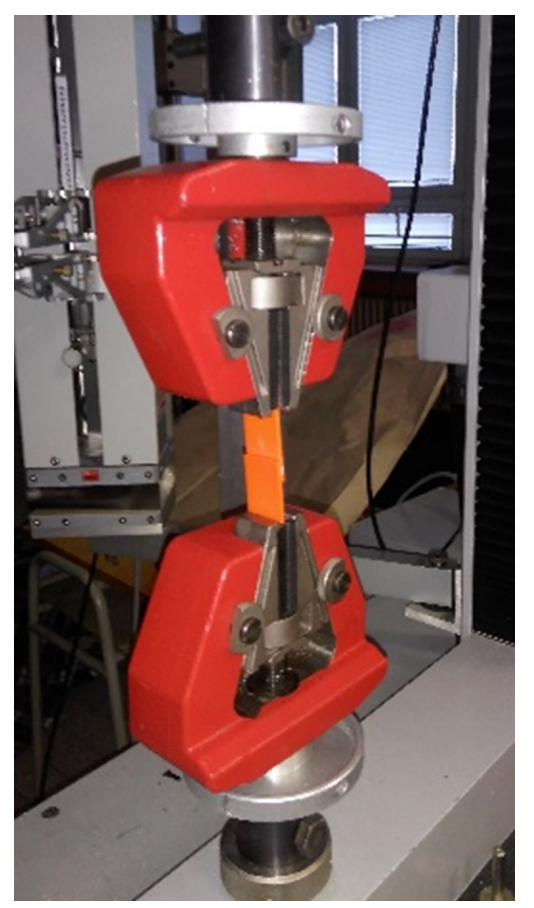

Figure 3. Samples fixed in the jaws of the Testometric machine M500/50CT.

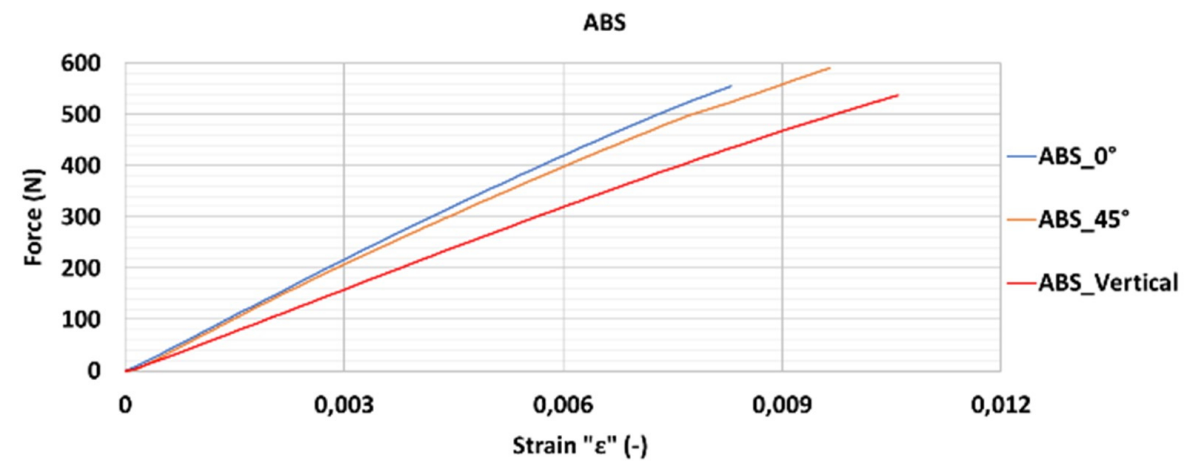

FiguRE 4. Force - strain graph for the ABS material.

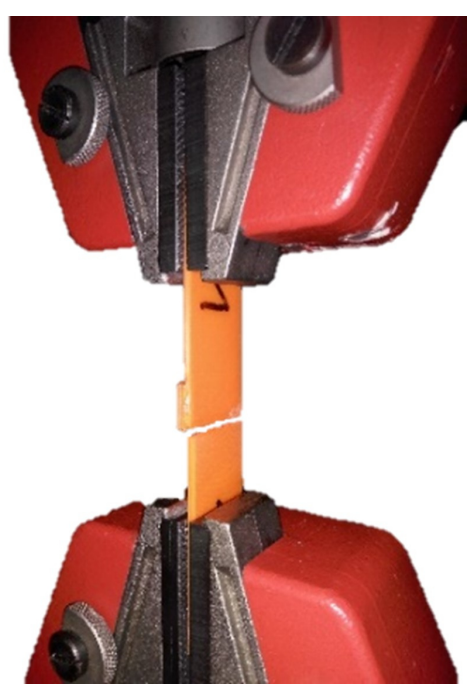

Figure 5. Force - strain graph for the ABS material. 


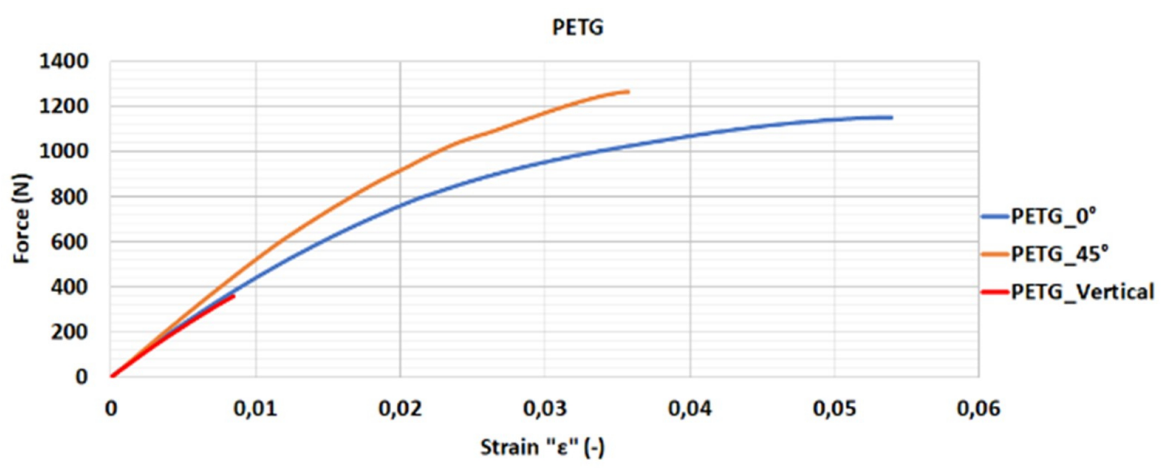

Figure 6. Force - strain graph for the PETG material.

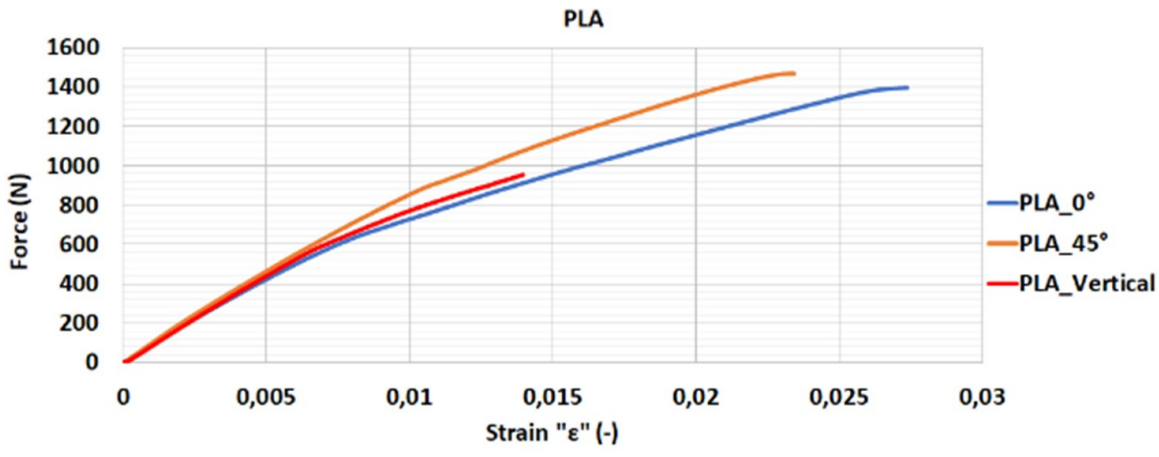

Figure 7. Force - strain graph for the PLA material.

is shown. Almost all samples broke around the load force of $560 \mathrm{~N}$. It can also be seen on the graph that the "vertical" sample (see Fig. 1) has a slightly different behaviour.

In the case of the ABS samples, the material broke first (as can be seen in Fig. 5), the adhesive bond proved to be stronger than the material itself. That also means that the orientation of the parts during printing does not have a significant impact on the adhesive bond strength.

The force - strain graph for the PETG material can be seen in Fig. 6. The samples with the orientation $0^{\circ}$ and $45^{\circ}$ broke around $1200 \mathrm{~N}$ and the "vertical" sample already at $360 \mathrm{~N}$. In the case of the PETG samples, the material broke first and the adhesive bond resisted the load. The orientation of the layers has an impact on the strength of the material, but not on the strength of the adhesive bond.

The force - strain graph for the PLA material can be seen in Fig. 7. The samples with the orientation $0^{\circ}$ and $45^{\circ}$ broke around $1450 \mathrm{~N}$. The "vertical" sample broke at $950 \mathrm{~N}$. Also in the case of this material, the material broke first and the adhesive bond resisted the load. The orientation of the layers has no impact on the strength of the adhesive bond.

Finally, Fig. 8 shows the results for the TPU material. All samples separated at approx. $420 \mathrm{~N}$, where the adhesive bond failed, and the parts tore off. After an examination of the contact surface, it was found out that the adhesion was not sufficient. The orientation of the layers did not affect the strength of

\begin{tabular}{lc}
\hline Material and its orientation $(-)$ & Force $(\mathrm{N})$ \\
\hline ABS_0 & $554.70 \pm 11.09$ \\
ABS_45 & $590.30 \pm 5.90$ \\
ABS_VERTICAL & $537.80 \pm 16.13$ \\
PETG_0 & $1149.50 \pm 11.50$ \\
PETG_45 & $1263.30 \pm 12.63$ \\
PETG_VERTICAL & $359.90 \pm 7.20$ \\
PLA_0 & $1396.30 \pm 27.93$ \\
PLA_45 & $1465.90 \pm 29.32$ \\
PLA_VERTICAL & $952.10 \pm 28.56$ \\
TPU_0 & $417.00 \pm 8.34$ \\
TPU_45 & $413.50 \pm 4.14$ \\
TPU_VERTICAL & $452.10 \pm 13.56$ \\
\hline
\end{tabular}

TABLE 1. Force for each material.

the glued joint. It is, however, worth noting that the "vertical" sample has a higher elasticity because of the way the layers are organised.

Fig. 10 shows all the graphs together. For better clarity, the horizontal axis is shorter, and thus the TPU graph is not completely visible.

Table 1 shows the values of the load force for each material and its orientation.

\section{SUMmary}

The research focuses on a verification of the strength of adhesive joints of parts created by the FFF method using the common materials ABS, PLA, PETG and 


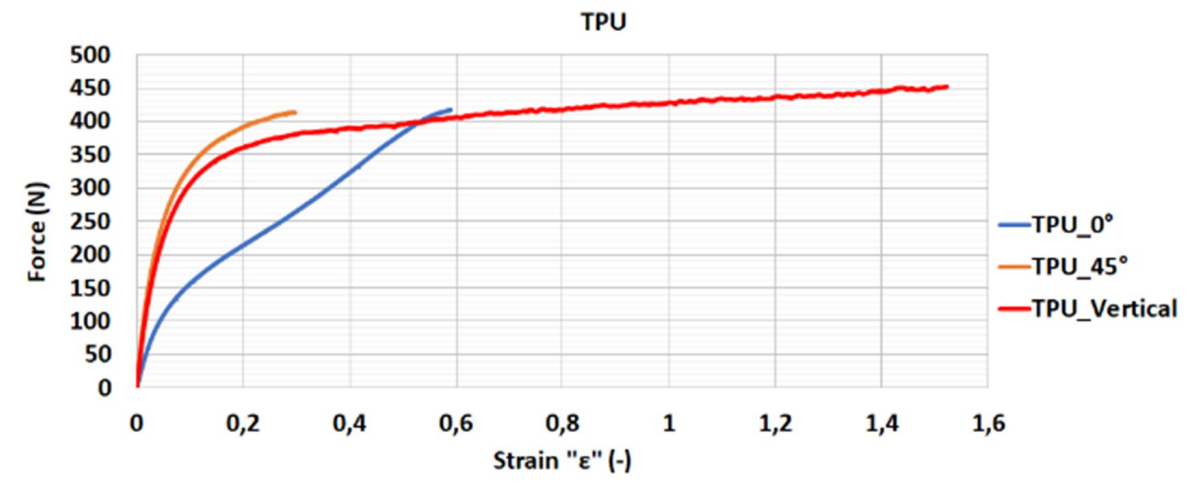

FIGURE 8. Force - strain graph for the TPU material.

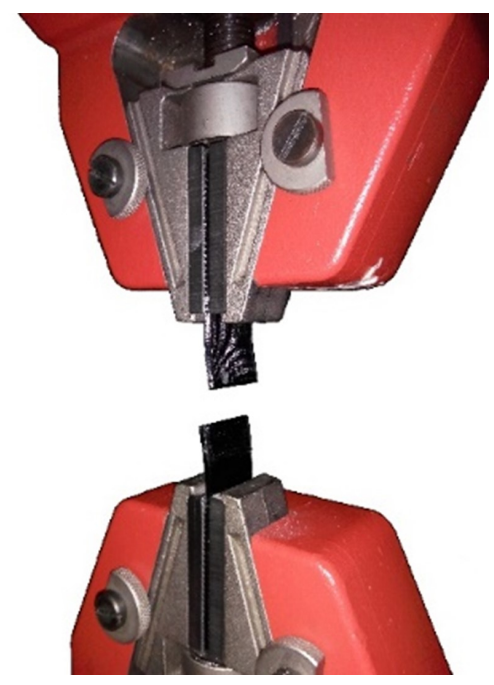

FIGURE 9. Separation of the adhesive joint of the TPU material.

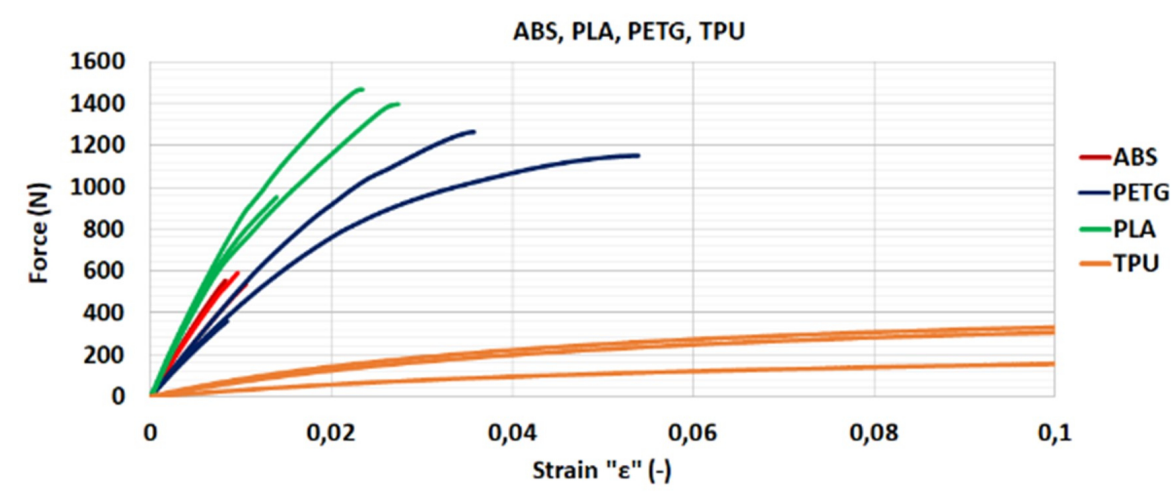

Figure 10. Comparison of all materials. 
TPU. The results show that for the ABS, PLA and PETG, the usage of the Loctite 406 adhesive is advantageous because for all the tested samples, the base material broke and not the joint. All the samples created from the TPU material broke in the adhesive joint - the glued surfaces separated. This can be caused either by bad adhesion of the glue to the surface or by a high elasticity and elongation of the TPU material - the hardened adhesive layer has a lower elasticity, and thus it tore off the material surface.

The tests also proved that the orientation of the layers of the printed parts does not affect the strength of the adhesive bond. That is evident mainly from the testing of the flexible TPU material, where all the glued joints broke at approximately the same force, but different elongations of the samples. However, the orientation of the layers of the printed parts does affect the strength of the material itself.

\section{Conclusion}

The testing has shown that the bond strength is higher than the strength of the base material at a given fill density. The layer orientation does not affect the strength of the adhesive bond, but it affects the strength of the material itself, in which the specimen breaks after overloading.

Glued joints of a flexible material (TPU) show a different behaviour from the glued joints of conventional materials. During the testing, the adhesive bond was damaged while the base material was not damaged. This behaviour can be the subject of a further research to find the best adhesive for flexible materials.

\section{ACKNOWLEDGEMENTS}

This article has been done with the support of the project Research Centre of Advanced Mechatronic Systems, reg. no. CZ.02.1.01/0.0/0.0/16_019/0000867 in the frame of the Operational Program Research, Development and Education. This article has also been supported by the Specific Research Project SP2019/69 and financed by the Ministry of Education, Youth and Sports of the Czech Republic.

\section{REFERENCES}

[1] R. Jiang, R. Kleer, F. T. Piller. Predicting the future of additive manufacturing: A Delphi study on economic and societal implications of 3D printing for 2030. Technological Forecasting and Social Change 117:84 97, 2017. DOI:10.1016/j.techfore.2017.01.006

[2] Y. He, G.-H. Xue, J.-Z. Fu. Fabrication of low cost soft tissue prostheses with the desktop 3D printer. Scientific Reports 4:1 - 7, 2014. DOI:10.1038/srep06973

[3] J. Zuniga, D. Katsavelis, J. Peck, et al. Cyborg beast: A low-cost 3d-printed prosthetic hand for children with upper-limb differences. BMC research notes 8(1):10, 2015. DOI:10.1186/s13104-015-0971-9

[4] J. Lipina, V. Krys, J. Sedlák. Shaped glued connection of two parts made by rapid prototyping technology. In Modeling and Optimization of the Aerospace, Robotics, Mechatronics, Machines-Tools, Mechanical Engineering and Human Motricity Fields, vol. 555 of Applied Mechanics and Materials, pp. 541 - 548. 2014. DOI:10.4028/www.scientific.net/AMM.555.541

[5] K. Silver, J. Potgieter, K. Arif, R. Archer. Opportunities and challenges for large scale 3D printing of complex parts. In 2017 24th International

Conference on Mechatronics and Machine Vision in Practice (M2VIP), vol. 2017 December, pp. 1 - 6. 2017. DOI:10.1109/M2VIP.2017.8211515

[6] Original Prusa i3 MK3 3D Printer. https://shop.prusa3d.com/cs/3d-tiskarny/181-3dtiskarna-original-prusa-i3-mk3s.html\# Accessed: 20 May 2020.

[7] T. Yao, J. Ye, Z. Deng, et al. Tensile failure strength and separation angle of FDM 3D printing PLA material: Experimental and theoretical analyses. Composites Part B: Engineering 188:107894, 2020. DOI:10.1016/j.compositesb.2020.107894

[8] S. Wang, Y. Ma, Z. Deng, et al. Effects of fused deposition modeling process parameters on tensile, dynamic mechanical properties of $3 \mathrm{D}$ printed polylactic acid materials. Polymer Testing 86:106483, 2020. DOI:10.1016/j.polymertesting.2020.106483

[9] J. Folta. Hodnocení pevnosti lepených spojů v konstrukci autobusu. Bachelor's thesis, University of Pardubice, Pardubice, 2018.

[10] B. M. Malyshev, R. L. Salganik. The strength of adhesive joints using the theory of cracks. International Journal of Fracture Mechanics 1(2):114 - 128, 1965. DOI:10.1007/BF00186749.

[11] ASTM D638 - 14 - Standard Test Method for Tensile Properties of Plastics. Standard, American Society for Testing and Materials, West Conshohocken, 2014.

[12] ČSN EN 1465 - Lepidla - Stanovení smykové pevnosti $\mathrm{v}$ tahu tuhých adherendů na přeplátovaných tělesech. Standard, Česká agentura pro standardizaci, Prague, 2009.

[13] K. Kim, J. Park, J. hoon Suh, et al. 3D printing of multiaxial force sensors using carbon nanotube (CNT)/thermoplastic polyurethane (TPU) filaments. Sensors and Actuators A: Physical 263:493 - 500, 2017. DOI:10.1016/j.sna.2017.07.020

[14] All3DP. 3D Printing Infill: The Basics - Simply Explained. https://all3dp.com/2/infill-3dprinting-what-it-means-and-how-to-use-it/ Accessed: 20 May 2020.

[15] Loctite 401/406/454: Instant adhesives. https://www . interempresas . net/Hardware/ Companies-Products/Product-Instant-adhesivesLoctite-Loctite-401-406-454-86539.html Accessed: 21 May 2020.

[16] Loctite 406 Technical Data Sheet. http://polymerteknik.com/doc/Loctite-406.pdf Accessed: 20 May 2020. 